\title{
Die Wiederkehr der 60er-Jahre
}

\section{Revival of the Sixties}

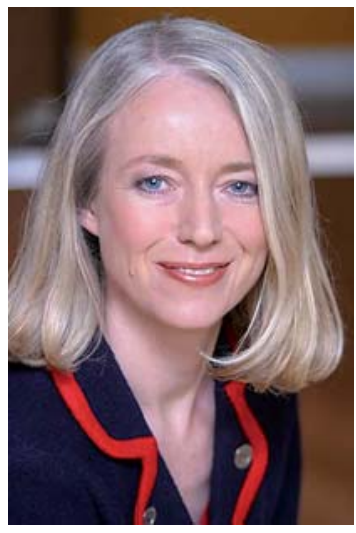

Prof. Dr. Christiane Bayerl
In diesem Heft können Sie sich einsehen in PopArt in der Histologie. Die Wissenschaft vom biologischen Gewebe wird von Anne Kerber, medizinisch-technische Assistentin in der Klinik für Dermatologie in Homburg/Saar, einmal ganz anders als im Pathologielehrbuch vorgestellt. Mit Fotoverarbeitungsprogrammen hat sie ausgewählte Bildausschnitte zu Pop-Art-Bildern umgewandelt. So sind ihr ganz neu anmutende Darstellungen von Haaren, Drüsen, Blutgefäßen, Muskel-, Knorpel- und Fettgewebe gelungen, jeweils in Pop-Art-Farbgebung, Kunst also. Das sollte doch jedem Dermatohistopathologen schmeicheln, wusste er doch schon immer, dass das, was er täglich tut, nicht nur wertvoll, sondern auch Kunst ist.

Kunst, dem Alltäglichen und Trivialen zugewandt, in einer Art der Darstellung, wie wir es von Comics von Roy Lichtenstein gewohnt sind, das ist PopArt. Die Farbpalette beschränkt sich meist auf die Primärfarben. Die Ränder sind deutlich schwarz konturiert. Zeitlich fast parallel, vielleicht etwas später, folgte die Hippie-Bewegung mit allen vorstellbaren Farben und starken Parfüms, dominiert vom Patchouli-Duft bzw. je nach Geschmack-Geruch, das Musical Hair, Jesus Christ Superstar, das „Jahr des Wassermanns“, Halluzinogene, Goa und Folk waren „angesagt“. Pop-Art zeigt dagegen die Begeisterung für den nach dem zweiten Weltkrieg wiedererlangten Wohlstand bzw. Kritik daran. Als späterer Filmemacher, Künstler und Verleger arbeitete Andy Warhol, einer der Hauptagonisten der Pop-Art, zunächst sehr erfolgreich als Industrie- und Werbegrafiker. Hollywoodstars wie Marilyn Monroe, Liz Taylor, Elvis Presley, James Dean aber auch Mao, Popeye und Superman waren seine Motive. Die quantitative Vervielfältigung auf der Leinwand, wie z. B. bei seiner Mona Lisa und den Dosensuppen mit der Etikettierung von Campbell's, die es in 32 Geschmacksrichtungen gab, faszinierte ihn. Warhol pflegte also das Wiederholen eines Motivs in Serie und das war es dann auch, was ihm zum künstlerischen Durchbruch verhalf. Und das ist auch das Erfolgsprinzip der Histologie geworden. Ein Schnitt sagt einiges, die Serienschnitte enthalten jedoch wesentlich mehr Information. Zudem setzt das, was wir am Mikroskop sehen, einen optischen Reiz, insbesondere durch die grelle Farbgebung, natürlich auch durch die Beleuchtung und das ist typisch für Pop-Art, grelle Farbgebung mit Acrylfarben und starken Kontrasten. Warhol war es, der bei seinen Lightshows in der „Factory“, einer Räumlichkeit, die Atelier, Filmstudio, Partyambiente und Bühne für Rockgruppen darstellte, Stroboskope einsetzte, also wiederum eine Bearbeitung des Themas Serienschnitte einer Abbildung, Wiederholung mit leichten Abwandlungen des Dargestellten. Denkt man an Andy Warhols Techniken, fallen den Freunden der Pop-Art als erstes die Siebdrucke ein, die dazu dienen, ein Motiv fast identisch in serieller Produktion immer wieder auf die Leinwand zu bringen. Bei der Histologie fallen uns als ursprünglichste Technik zunächst die Serienschnitte ein. Die Farben für die histologischen Präparate aus Pflanzen- und Tierwelt sind jedoch deutlich älter als Acrylfarben und waren zunächst aus der Pflanzenwelt wie die Färberkrappflanze, die im 18. Jh. eingesetzt wurde, um Tierknochen zu färben. Karmin und Haematoxylin folgten und dann die Anilinfarbstoffe mit Paul Ehrlich. Das Mikrotom für Gewebeschnitte wurde von Vater und Sohn Chevalier in der Pariser Firma konstruiert, die sich seit 1765 der Herstellung wissenschaftlicher Instrumente verschrieben hatte. Johannes Müller schrieb 1838 ein Buch über die Struktureigenschaften von Krebs. Als Vater der Histopathologie wird Rudolf Virchow (18211902) angesehen.

Pop-Art-Kunst vom Arbeitsplatz zeigt Ihnen Frau Anne Kerber, also aus dem Alltäglichen transformiert und zwar nicht als Dosenkost zubereitet, sondern individuell ausgewählt und auch in einer breiteren Farbpalette als Warhol sie eingesetzt hatte, eher in der ganzen Breite der psychedelischen Farben der Hippie-Szene, ein Happening eben!

\section{Viel Spaß}

Ihre

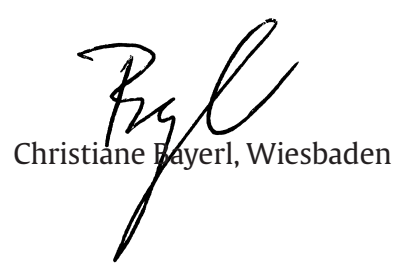

